\title{
Health and economic benefits of building ventilation interventions for reducing indoor PM2.5 exposure from both indoor and outdoor origins in urban Beijing, China
}

Article

Accepted Version

Creative Commons: Attribution-Noncommercial-No Derivative Works 4.0

Yuan, Y., Luo, Z., Liu, J., Wang, Y. and Lin, Y. (2018) Health and economic benefits of building ventilation interventions for reducing indoor PM2.5 exposure from both indoor and outdoor origins in urban Beijing, China. Science of the Total Environment, 626. pp. 546-554. ISSN 0048-9697 doi: https://doi.org/10.1016/j.scitotenv.2018.01.119 Available at https://centaur.reading.ac.uk/74886/

It is advisable to refer to the publisher's version if you intend to cite from the work. See Guidance on citing.

To link to this article DOI: http://dx.doi.org/10.1016/j.scitotenv.2018.01.119

Publisher: Elsevier

All outputs in CentAUR are protected by Intellectual Property Rights law, including copyright law. Copyright and IPR is retained by the creators or other copyright holders. Terms and conditions for use of this material are defined in the End User Agreement. 


\section{www.reading.ac.uk/centaur}

\section{CentAUR}

Central Archive at the University of Reading

Reading's research outputs online 
1 Manuscript revised to Science of the Total Environment, Dec 2017

2 Health and economic benefits of building ventilation interventions for reducing indoor

3 PM2.5 exposure from both indoor and outdoor origins in urban Beijing, China.

5 Ye Yuan ${ }^{1,2}$, Zhiwen Luo ${ }^{2, *}$, Jing Liu ${ }^{3, *}$, Yaowu Wang ${ }^{1}$, Yaoyu Lin ${ }^{1}$

6

7

8

1. School of Architecture and Urban Planning, Harbin Institute of Technology (Shenzhen), Shenzhen, China.

2. School of the Built Environment, University of Reading, United Kingdom.

3. School of Architecture, Harbin Institute of Technology, Harbin, China.

\section{Word count of abstract: 241}

Word count of text: 5959

*Correspondence author:

Dr Zhiwen Luo, School of the Built Environment, University of Reading, United Kingdom

Email: z.luo@reading.ac.uk

Prof Jing Liu, School of Architecture, Harbin Institute of Technology, China

Email: liujinghit0@163.com 
Nomenclature:

\begin{tabular}{lllllll}
\multicolumn{2}{c}{ Variables } & $N$ & Population & \multicolumn{2}{l}{ Subscripts } \\
$A$ & Floor area & $P$ & Penetration factor & $B E$ & Building energy \\
$a$ & Per capita floor area & $p$ & Price & $c$ & Cooling \\
$A C R$ & Air change rate & $Q$ & Building energy load & $E$ & Exhausted air \\
$C$ & PM $_{2.5}$ Concentration & $q$ & Specific enthalpy of air & $e$ & Electricity \\
$c$ & Specific heat & $S$ & Indoor emission rate & $h$ & Heating \\
$D$ & Electric power & $t$ & Temperature & $I$ & Infiltration \\
$d$ & Humidity & $V$ & Indoor volume & $I A$ & Indoor air \\
$E B$ & Economic benefit & $V S L$ & Value of statistical life & $O A$ & Outdoor air \\
$F$ & Flow volume & $\beta$ & Concentration-response & $p$ & Ground source heat pump \\
$H$ & Annual health risk cases & & (C-R) coefficient & $r$ & Room air conditioning \\
$K$ & Deposition rate & $\eta$ & Efficiency & $V$ & Mechanical ventilation \\
$M$ & Annual monetary cost & $\rho$ & Air density & $V F$ & Mechanical ventilation filter \\
$m$ & Annual mortality rate & $\tau$ & Time & $V P$ & Mechanical ventilation power
\end{tabular}

\section{Abstract:}

27 China is confronted with serious $\mathrm{PM}_{2.5}$ pollution, especially in the capital city of Beijing. Exposure to $28 \mathrm{PM}_{2.5}$ could lead to various negative health impacts including premature mortality. As people spend most of their time indoors, the indoor exposure to $\mathrm{PM}_{2.5}$ from both indoor and outdoor origins constitutes the majority of personal exposure to $\mathrm{PM}_{2.5}$ pollution. Different building interventions have been introduced to mitigate indoor $\mathrm{PM}_{2.5}$ exposure, but always at the cost of energy expenditure. In this study, the health and economic benefits of different ventilation intervention strategies for reducing indoor $\mathrm{PM}_{2.5}$ exposure are modelled using a representative urban residence in Beijing, with consideration of different indoor $\mathrm{PM}_{2.5}$ emission strengths and outdoor pollution. Our modelling results show that the increase of envelope air-tightness can achieve significant economic benefits when indoor $\mathrm{PM}_{2.5}$ emissions are absent; however, if an indoor $\mathrm{PM}_{2.5}$ source is present, the benefits 
37 only increase slightly in mechanically ventilated buildings, but may show negative benefit without

38 mechanical ventilation. Installing mechanical ventilation in Beijing can achieve annual economic

39 benefits ranging from 200yuan/capita to 800yuan/capita if indoor $\mathrm{PM}_{2.5}$ sources exist. If there is no

40 indoor emission, the annual benefits above 200yuan/capita can be achieved only when the $\mathrm{PM}_{2.5}$

41 filtration efficiency is no less than $90 \%$ and the envelope air-tightness is above Chinese National

42 Standard Level 7. Introducing mechanical ventilation with low $\mathrm{PM}_{2.5}$ filtration efficiency to current

43 residences in urban Beijing will increase the indoor $\mathrm{PM}_{2.5}$ exposure and result in excess costs to the

44 residents.

45 Keywords: $\mathrm{PM}_{2.5}$; building ventilation; health; energy; economic benefit; indoor exposure

46

47

48

49

50

51

52

53

54

55

56

57

58

59

60

61 
With the rapid urbanization and economic growth of the past few decades, China is confronted with degrading urban air quality, especially in mega-cities. $\mathrm{PM}_{2.5}$ pollution has become one of the most serious environmental hazards in China and attracts global attention (Fang et al., 2016). Beijing is the capital of China and is located in the most $\mathrm{PM}_{2.5}$ polluted regions of China. According to the China Environmental Status Bulletin (2016), the annual mean $\mathrm{PM}_{2.5}$ concentration in Beijing was $81 \mu \mathrm{g} / \mathrm{m}^{3}$ in 2015 , which is over twice the interim target $-1\left(35 \mu \mathrm{g} / \mathrm{m}^{3}\right)$ and eight times the guideline $\left(10 \mu \mathrm{g} / \mathrm{m}^{3}\right)$ recommended by the World Health Organization (WHO, 2006). The citizens of Beijing were exposed to the highest $\mathrm{PM}_{2.5}$ concentration among all Chinese cities, with 91\% (2014), 86\% (2015) and 73\% (2016) of the city's population exceeding $70 \mu \mathrm{g} / \mathrm{m}^{3}$ exposure (Song et al., 2017).

Epidemiological studies have demonstrated that exposure to $\mathrm{PM}_{2.5}$ is associated with many types of negative health consequences. According to the global study conducted by the Global Burden of Diseases (GBD) in 2015, ambient $\mathrm{PM}_{2.5}$ air pollution contributed to an estimated increased mortality by $17.1 \%$ from ischaemic heart disease, $14.2 \%$ from cerebrovascular disease, $16.5 \%$ from lung cancer, $24.7 \%$ from lower respiratory infections, and $27.1 \%$ from chronic obstructive pulmonary disease (Cohen et al, 2017). Ambient $\mathrm{PM}_{2.5}$ has become the fifth-ranking mortality risk factor and cause 4.2 million (with 1.1 million contributed by China) annual mortality cases. However, the majority of the exposure actually occurs indoors as people spend about $90 \%$ of their time indoors (Klepeis et al., 2001; Ji and Zhao, 2015(a)), and the outdoor pollutants can penetrate into a building's interior space and cause indoor exposure to $\mathrm{PM}_{2.5}$ of ambient origins. Ji and Zhao (2015(b)) estimated that the mortality directly derived from indoor exposure to particles of outdoor origins accounted for $81 \%-89 \%$ of the total increase in mortality associated with exposure to outdoor PM pollution. Hänninen and Asikainen (2013) also reported that in the Europe Union in 2010, 1.28 million burdens of disease were estimated to be caused by indoor exposures to outdoor air pollution. require a long-term effort by several generations, as happened in the western world decades ago, to diminish the outdoor pollution emissions and clean up the atmosphere. Therefore, for the benefit of 
Chinese public welfare, the emergent short-term challenge is to impose effective, yet inexpensive, interventions to reduce such exposure risk that are affordable for typical Chinese households. Increase of building air-tightness and the installation of mechanical ventilation with effective filtration are regarded as two major interventions at the building scale to reduce indoor exposure to outdoor PM pollution. Increasing the air-tightness of the building could effectively prevent the ingress of outdoor pollution and reduce the energy cost for heating in winter, but at the same time, it could lead to a reduced capacity for diluting the indoor-generated emissions (Shrubsole et al., 2012). On the other hand, the introduction of mechanical ventilation could effectively ventilate the indoor space, but will potentially introduce pollutants from outdoors depending on the effectiveness of filtration.

Mechanical ventilation always comes with a higher cost of energy compared with non-mechanical methods. Furthermore, the indoor human activities such as cooking, smoking and household cleaning can elevate short-term indoor $\mathrm{PM}_{2.5}$ concentrations by as much as several orders of magnitude and make a significant contribution to indoor particle exposures (Long et al., 2000; Dimitroulopoulou et al., 2006; McGrath et al., 2017). The health benefits and economic costs of those interventions differ significantly, and remain largely unquantified. A holistic understanding of energy cost and health consequences for different ventilation interventions in response to both indoor and outdoor emissions is necessary.

Several existing studies have investigated the building ventilation interventions to reduce indoor exposure to outdoor PM pollution. Chen et al. (2016) modelled the indoor $\mathrm{PM}_{2.5}$ concentrations of six offices in China, showing that increasing the air-tightness of the buildings' external windows could effectively prevent the infiltration of outdoor particles and improve the indoor air quality. Zhao et al. (2015) estimated that residential ventilation systems with higher filtration efficiencies could reduce premature mortality and yield monetary benefits, especially in old residences with low air-tightness, but could also adversely influence outdoor particle infiltration if improperly installed (Stephens, 2015). Some researchers further combined the estimates from health impacts and operation costs. Montgomery et al. (2015) modified the ventilation system and filter efficiencies in an office building and compared the indoor particle concentrations, operation costs and monetized health benefits to occupants for a number of cities around the world. Results showed that, although the operation cost of 
117 filtration systems varied by a factor of 3 between cities, the monetized health benefits of filter

118 installations outweighed the operation costs by up to a factor of 10 , and the net benefits were greatest

119 for the highest efficiency filters. Zuraimi (2007) compared the economic benefits of health risk

120 reduction to the monetary cost of building interventions in Singapore, demonstrating that ventilation

121 strategies and filtration efficiencies can greatly influence $\mathrm{PM}_{10}$ exposure and its estimated impacts on population health with the health benefits being much larger than the operating costs. However, a similar study conducted in Toronto, Canada showed that the health benefits may not always outweigh the operating and retrofit costs, depending on the reference building model and the retrofit strategies (Zuraimi and Tan, 2015). Moreover, the above-mentioned studies only considered indoor particles of outdoor origin.

Some other researchers only considered the indoor particle emission and therefore the effect of the building ventilation interventions. Spilak et al. (2014) studied 27 dwellings in Denmark and found that indoor $\mathrm{PM}_{2.5}$ concentrations were strongly associated with building characteristics and indoor

$130 \mathrm{PM}_{2.5}$ sources, and particle filtration units could effectively reduce the $\mathrm{PM}_{2.5}$ levels in dwellings by more than half. The simulation studies on indoor $\mathrm{PM}_{2.5}$ concentrations in British dwellings showed that reductions in envelope permeability could decrease indoor $\mathrm{PM}_{2.5}$ exposure if combined with mechanical ventilation and heat recovery systems, but would lead to substantial increases in indoor $\mathrm{PM}_{2.5}$ concentrations if without mechanical ventilation (Shrubsole et al., 2012; Milner et al., 2015). According to the brief review above, the studies on the economic benefits of building ventilation interventions which combined health risk and operation cost only focused on $\mathrm{PM}_{2.5}$ from outdoor 137 origins, while the studies that considered $\mathrm{PM}_{2.5}$ from both outdoor and indoor origins only focused on 138 the reduction of indoor exposure instead of the consequent combined health and economic impacts. In 139 China, due to the large population nationwide, most urban residences are multi-storey apartments 140 without purpose-built mechanical ventilation systems. The Chinese cooking style is quite different from those of the west, leading to substantial particle emissions indoors (Lee et al., 2001; He et al., 2004(b)). Considering the above two national features and the high level of ambient $\mathrm{PM}_{2.5}$ pollution in 143 Beijing, the health and economic impacts of building ventilation interventions on urban residences in 144 Beijing may show distinct characteristics compared to the existing studies, and is therefore worthy of 
detailed investigation. The overarching aim of this paper is to evaluate and prioritize the potential health benefit and economic cost of different ventilation intervention strategies in order to reduce the indoor exposure to $\mathrm{PM}_{2.5}$ pollution of both outdoor and indoor origins for representative urban residential buildings in Beijing, China.

\section{Methods}

The modelling framework of the present study is illustrated by Fig.1. We first consider a basic scenario representing the current residential ventilation situation in urban Beijing, and different interventions are proposed to improve the current situation in response to the outdoor air pollution. The public health benefit from indoor $\mathrm{PM}_{2.5}$ pollution after intervention $\left(E B_{\text {health }}\right)$, and the energy cost due to building ventilation $\left(E B_{\text {energy }}\right)$ are therefore estimated. The uniqueness of the framework is to convert the public health impact and energy consumption into monetary values to make them comparable within a unified platform. The total economic benefit $\left(E B_{\text {total }}\right)$ can be estimated as:

$$
E B_{\text {total }}=E B_{\text {health }}+E B_{\text {energy }}
$$

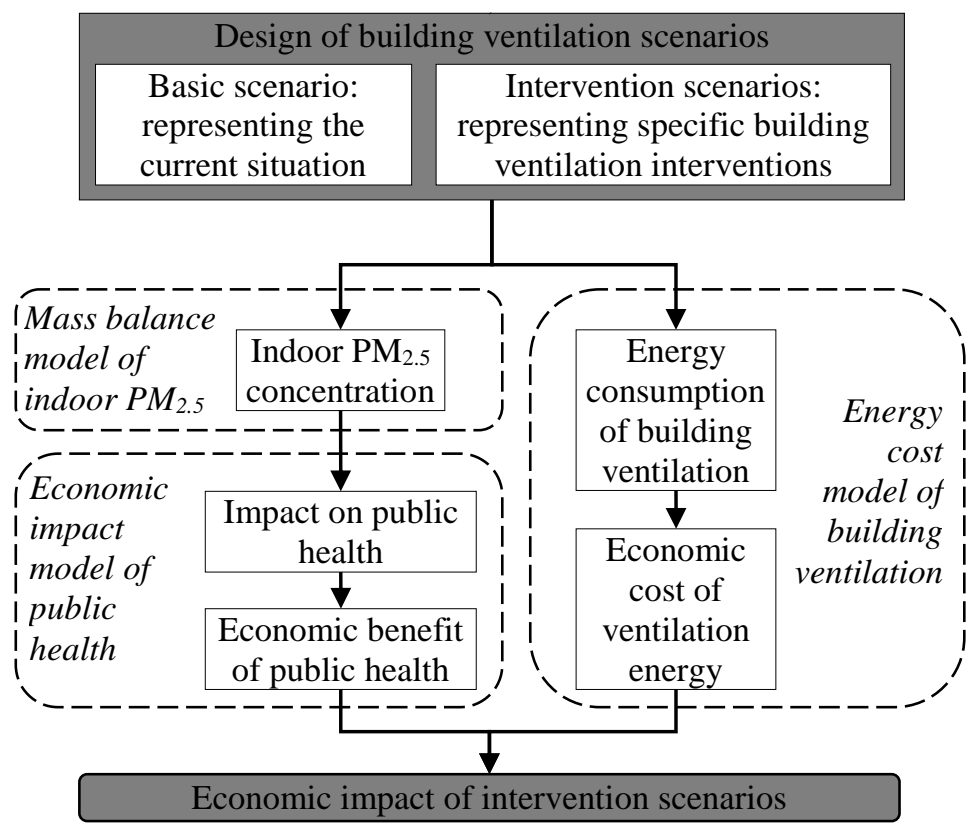


Being the first step of this study, an idealized representative urban apartment in Beijing is assumed as the model subject. This apartment is located on the 6th floor, which is estimated to be half-way up the average residential building. Accommodating a typical Beijing family (working parents and a school child), the number of occupants in the model apartment is assumed to be 3 , and the number of bedrooms is 2. According to the Beijing statistical yearbook (2016), the per capita residential area of urban households in Beijing is $31.69 \mathrm{~m}^{2}$ in 2015 . Therefore, the floor area of the apartment measures $8 \mathrm{~m} \times 12.5 \mathrm{~m}$, and the ceiling height is $2.8 \mathrm{~m}$ (the indoor volume $=280 \mathrm{~m}^{3}$ ). Windows are placed on southern and northern external walls. The opening joint length on each side is $24 \mathrm{~m}$. The height of the central line of the windows is $1.6 \mathrm{~m}$, and the total height of the central line of the window from the ground is estimated to be $18 \mathrm{~m}$. The external windows are assumed closed during the modelling, meaning there is no natural ventilation in the apartment.

Cooking and smoking are two common indoor residential $\mathrm{PM}_{2.5}$ sources. Because the contribution to indoor $\mathrm{PM}_{2.5}$ concentrations from cooking activities are tens of times greater than smoking $(\mathrm{He} e t$ al., 2004(a); Fabian et al., 2012), and Chinese smokers and their families are more aware of their health nowadays, cooking is considered as the only indoor $\mathrm{PM}_{2.5}$ source in the present modelling. In Chinese urban households, local exhausts such as range hoods are widely used while cooking. Therefore, in this analysis, a range hood with an exhaust flow as $10 \mathrm{~m}^{3} / \mathrm{min}$ (the minimum volume provided by the National Standard of China GB/T17713-2011 (AQSIQ and SAC, 2011)) is installed in the model apartment, which only runs when the cooking activities are present.

\subsection{Scenarios design}

Fig.2 presents a simplified schematic diagram of the fate and transport of $\mathrm{PM}_{2.5}$ in the indoor space model. The building ventilation interventions to reduce indoor exposure to both indoor and outdoor $\mathrm{PM}_{2.5}$ pollution involve changes in air-tightness levels (ATL) of the building envelope and the installation of mechanical ventilation with different $\mathrm{PM}_{2.5}$ filtration efficiencies (PFE) (natural ventilation is not considered here as it is mainly determined by human behaviour, which is not the scope of current study). The economic benefits of different interventions are evaluated relative to the current building ventilation situation. Therefore, in the following analysis, scenarios are designed as 


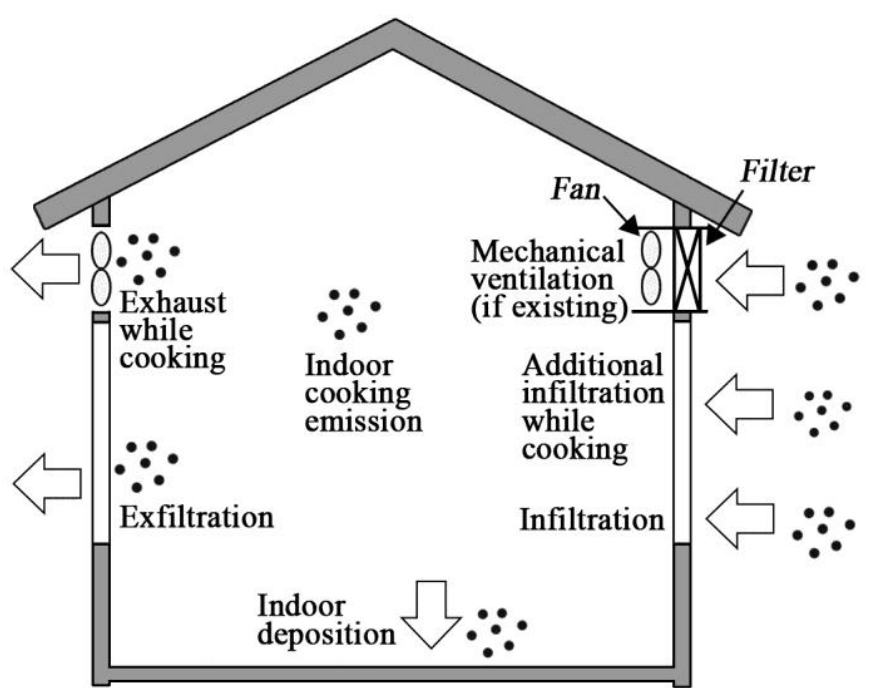

Fig.2: Simplified schematic of the fate and transport of indoor $\mathrm{PM}_{2.5}$

\subsubsection{Basic scenario}

The basic scenario is considered as infiltration only without mechanical ventilation, which represents the general urban buildings in Beijing. The infiltration airflow is induced by the wind and stack effects, and strongly influenced by the air-tightness level of the external windows. According to National Standard of China GB/T7106-2008, there are eight air tightness levels (ATLs). We calculated the annual infiltration airflow rate with respect to each ATL for our model building, as shown in Fig.3. The detail calculation procedure of combined wind-and-buoyancy driven infiltration airflow is introduced in the Supplement Information (SI1). The annual average air change rate of urban apartments in Beijing with windows closed was found to be around $0.21 / \mathrm{h}$ as determined by Shi et al. (2015) by both numerical simulations and field measurement. Our prediction with ATL3 matches well with the work from Shi et al. (2015). Therefore, the model building with ATL3 without mechanical ventilation can best represent the current situation as the basic scenario. 


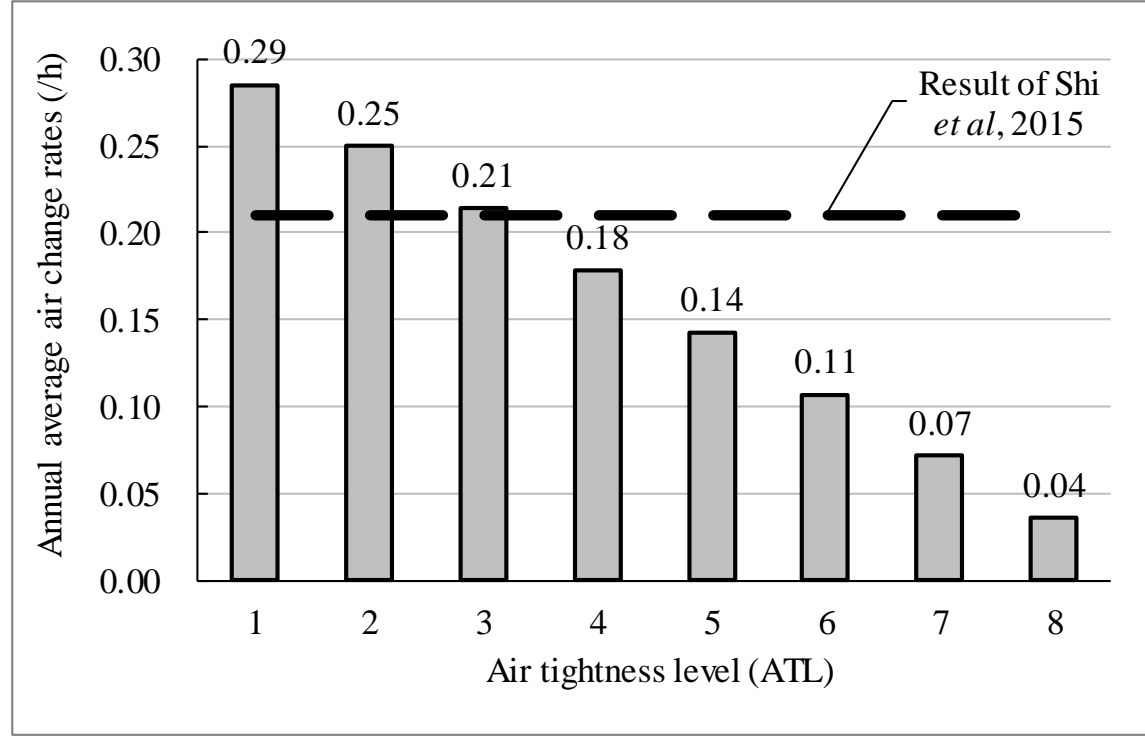

Fig.3: Annual average air change rates of the model building with different air-tightness levels

\subsubsection{Intervention scenarios}

All the intervention scenarios are listed in Table 1, considering different ATLs and $\mathrm{PM}_{2.5}$ filtration efficiencies (PFE) for mechanical ventilation. ATL5 and ATL7 are requirements from the Industry

211 Standard of China JGJ26-2010 (MOHURD, 2010) and the Local Standard of Beijing DB11/891-2012

212 (BMCUP and BMAQTS, 2012), respectively. Currently in China, the $\mathrm{PM}_{2.5}$ filtration efficiency (PFE)

213 has not been standardized in national standards for air filters (AQSIQ and SAC, 2008(a), (c)). PFE is

214 graded into 4 levels from 50\% to 99\%. For each intervention scenario, the letter "A" and "F" stand for air-tightness level and the $\mathrm{PM}_{2.5}$ filtration efficiency of the mechanical ventilation system; "NV" stands for no mechanical ventilation; the numbers stand for the corresponding level and efficiency

217 (\%). For example, A5NV represents the intervention scenario with air tightness level increases from 218 basic scenario of ATL3 to ATL5, without mechanical ventilation. A3F50 represents the intervention 219 scenario with air tightness level 3 and mechanical ventilation with filtration efficiency of 50\%. 
Table 1: Design of the intervention scenarios

\begin{tabular}{|c|c|c|c|}
\hline $\begin{array}{l}\text { Intervention } \\
\text { scenarios }\end{array}$ & $\begin{array}{l}\text { Mechanical } \\
\text { ventilation }\end{array}$ & $\begin{array}{c}\text { Air-tightness levels } \\
\text { (ATL) }\end{array}$ & $\begin{array}{l}\mathrm{PM}_{2.5} \text { filtration efficiencies of } \\
\text { mechanical ventilation (PFE) }\end{array}$ \\
\hline A5NV & $x$ & 5 & - \\
\hline A7NV & $x$ & 7 & - \\
\hline A3F50 & $\sqrt{ }$ & 3 & $50 \%$ \\
\hline A3F70 & $\sqrt{ }$ & 3 & $70 \%$ \\
\hline A3F90 & $\sqrt{ }$ & 3 & $90 \%$ \\
\hline A3F99 & $\sqrt{ }$ & 3 & $99 \%$ \\
\hline A5F50 & $\sqrt{ }$ & 5 & $50 \%$ \\
\hline A5F70 & $\sqrt{ }$ & 5 & $70 \%$ \\
\hline A5F90 & $\sqrt{ }$ & 5 & $90 \%$ \\
\hline A5F99 & $\sqrt{ }$ & 5 & $99 \%$ \\
\hline A7F50 & $\sqrt{ }$ & 7 & $50 \%$ \\
\hline A7F70 & $\sqrt{ }$ & 7 & $70 \%$ \\
\hline A7F90 & $\sqrt{ }$ & 7 & $90 \%$ \\
\hline A7F99 & $\sqrt{ }$ & 7 & $99 \%$ \\
\hline
\end{tabular}

\subsection{Modelling methodologies}

\subsubsection{The mass balance model of indoor $\mathbf{P M}_{2.5}$}

Because particles emitted during cooking can disperse quickly from the kitchen to the living room and impact all occupants in the residence (Wan et al., 2011), the model apartment is simplified as a well-mixed single compartment. Based on this assumption and the fate and transport of indoor $\mathrm{PM}_{2.5}$ shown in Fig.2, the dynamic mass balance model is:

where $V$ is the indoor volume $\left(280 \mathrm{~m}^{3}\right) ; C_{I A}$ is the indoor $\mathrm{PM}_{2.5}$ concentration; $C_{O A}$ is the outdoor $\mathrm{PM}_{2.5}$ concentration; $P$ is the penetration factor for $\mathrm{PM}_{2.5}$ entering via air infiltration; $F_{I}$ is the infiltration 
231 airflow caused by wind and stack effects, $F_{R H, I}$ is the infiltration airflow caused by the exhaust of the

232 range hood while cooking; $\eta_{V F}$ is the $\mathrm{PM}_{2.5}$ removal efficiency of the filter in the ventilation system;

$233 F_{V}$ is the ventilation airflow; $S$ is the indoor $\mathrm{PM}_{2.5}$ emission rate; $F_{E}$ is the exfiltration airflow; $F_{R H, E}$ is

234 the exhaust airflow by the range hood while cooking, $\left(16 \mathrm{~m}^{3} / \mathrm{min}\right) ; K$ is the deposition rate for $\mathrm{PM}_{2.5}$.

235 The dynamic mass balance model can be described in a discrete form. The indoor $\mathrm{PM}_{2.5}$

236 concentration at time step $\tau+\Delta \tau$ is:

$$
\left.C_{I A}\right|_{\tau+\Delta \tau}=\left.C_{I A}\right|_{\tau} \cdot e^{-x \Delta \tau / V}+\frac{\left.y \cdot C_{O A}\right|_{\tau+\Delta \tau}+\left.S\right|_{\tau+\Delta \tau}}{x}\left(1-e^{-x \Delta \tau / V}\right)
$$

where

In the following modelling, because cooking activities usually last for a few minutes, the time step

$\Delta \tau$ is set at $1 \mathrm{~min}$. The indoor $\mathrm{PM}_{2.5}$ concentrations of $1 \mathrm{~min}$ intervals for a whole year (totally 525,600 steps) are considered. The initial indoor concentration $\left(\left.C_{I A}\right|_{t=0}\right)$ is calculated by the steady-state form.

Hourly ambient data, such as concentrations, temperatures and wind velocities, are discreted to 60 minutes and assumed constant within the whole hour.

The determination of all the parameters in the mass balance model is described in the Supplement Information (SI2). We also consider different cooking durations to take into account the contribution

247 of indoor emission. The cooking minutes for each daily meal are classified into four groups, as listed 248 in Table 2.

Table 2: Setting of daily cooking times

\begin{tabular}{ccccccc}
\hline \multirow{2}{*}{ Group } & \multicolumn{2}{c}{ Breakfast } & \multicolumn{2}{c}{ Lunch } & \multicolumn{2}{c}{ Supper } \\
& Daily period & Duration & Daily period & Duration & Daily period & Duration \\
\hline 1 & None & $0 \mathrm{~min}$ & None & $0 \mathrm{~min}$ & None & 0 min \\
2 & $7: 00 \sim 7: 10$ & $10 \mathrm{~min}$ & $12: 00 \sim 12: 20$ & $20 \mathrm{~min}$ & $19: 00 \sim 19: 20$ & $20 \mathrm{~min}$ \\
3 & $7: 00 \sim 7: 20$ & $20 \mathrm{~min}$ & $12: 00 \sim 12: 40$ & $40 \mathrm{~min}$ & $19: 00 \sim 19: 40$ & $40 \mathrm{~min}$ \\
4 & $7: 00 \sim 7: 30$ & $30 \mathrm{~min}$ & $12: 00 \sim 13: 00$ & $60 \mathrm{~min}$ & $19: 00 \sim 20: 00$ & $60 \mathrm{~min}$ \\
\hline
\end{tabular}




\subsubsection{Economic impact model of public health}

Most of the epidemiologic studies linking air pollution and health endpoints are based on a relative risk model in the form of a Poisson regression (Kan and Chen, 2004). The health risk can be calculated using the concentration-response (C-R) coefficient (Huang and Zhang, 2013):

$$
H=H_{0} \cdot \exp \left(\beta \cdot\left(C-C_{0}\right)\right)
$$

where $C$ and $H$ are the annual pollutant concentration and annual health endpoint; $\beta$ is the concentration-response (C-R) coefficient, representing the excess health risk per each $1 \mu \mathrm{g} / \mathrm{m}^{3}$ increase in $\mathrm{PM}_{2.5} ; C_{0}$ is the threshold concentration, below which there is no observed health effect; $H_{0}$ is the baseline incidence under $C_{0}$. So far, in China, studies on concentration-response relationships derived from long-term exposure to $\mathrm{PM}_{2.5}$ have been largely absent (Shang et al., 2013). A C-R coefficient of 0.4\% provided by Pope et al. (2002), which is widely used for evaluating the health risk of long-term $\mathrm{PM}_{2.5}$ exposure, is adopted in the present study.

Considering both the indoor and outdoor exposures, the pollutant concentration $C$ is determined as the time-weighted annual average concentration, which is calculated as:

$$
C=\frac{\tau_{I A} \cdot \overline{C_{I A}}+\tau_{O A} \cdot \overline{C_{O A}}}{24}
$$

where $\tau_{I A}$ and $\tau_{O A}$ are the daily indoor and outdoor exposure hours, $\overline{C_{I A}}$ and $\overline{C_{O A}}$ are annual average indoor and outdoor concentrations. According to the review by Zhou and Zhao (2012), the indoor and outdoor time that Chinese adults spent per day are estimated to be 21.1 and 2.9 hours, respectively.

There is no lower threshold yet identified for the health effects of $\mathrm{PM}_{2.5}$. In this analysis, because the basic scenario is representing the current situation, the corresponding health risk can be calculated relative to the basic scenario, as follows:

$$
H^{\prime}=N \cdot m=H_{0} \cdot \exp \left(\beta \cdot\left(C^{\prime}-C_{0}\right)\right)
$$

where $H^{\prime}, N$, and $m$ are the annual mortality cases, population $(18,777,000)$, and annual mortality rate (0.495\%) of urban Beijing, 2015, respectively; $C^{\prime}$ is the time-weighted annual average concentration in the basic scenario. 
Therefore, combining Equations (5) and (7), the health effect of the intervention scenarios compared to the basic scenario can be calculated as follows:

$$
\Delta H=N \cdot m \cdot\left[\exp \left(\beta \cdot\left(C-C^{\prime}\right)\right)-1\right]
$$

where $\Delta H$ is the difference of mortality cases between the intervention scenario and the basic scenario. A negative $\Delta H$ means a reduction of mortality cases.

The economic impact of public health is assessed by using the value of a statistical life (VSL, Viscusi and Aldy, 2003). Unlike the value of an actual life, the VSL is the value that an individual places on a marginal change in the likelihood of death. According to the research by Xie (2011), VSL is 16.8 million yuan per capita in Beijing. Therefore, the corresponding annual per capita economic benefit can be estimated by:

$$
E B_{\text {health }}=-\frac{\Delta H \cdot V S L}{N}
$$

\subsubsection{Energy cost of building ventilation}

The economic cost of energy consumption of the building ventilation $\left(M_{B E}\right)$ consists of three components: the heating and cooling energy cost of infiltration airflows $\left(M_{I}\right)$, the heating and cooling energy cost of mechanical ventilation airflows $\left(M_{V}\right)$, and the fan power cost of the mechanical ventilation system $\left(M_{V P}\right)$.

$$
M_{B E}=M_{I}+M_{V}+M_{V P}
$$

The heating and cooling energy cost of infiltration airflows $\left(M_{I}\right)$ are derived from the corresponding heating and cooling loads $\left(Q_{I, h}\right.$ and $\left.Q_{I, c}\right)$ of the model apartment:

$$
M_{I}=\frac{a \cdot p_{e}}{10^{3} A \cdot \eta_{c, r}} \int Q_{I, c} \mathrm{~d} \tau+\frac{a \cdot p_{h}}{10^{3} A} \int Q_{I, h} \mathrm{~d} \tau
$$

where $a$ is the urban per capita residential floor area in Beijing $\left(31.69 \mathrm{~m}^{2}\right) ; p_{e}$ is the mean value of the current civil electricity price in Beijing, $0.5 \mathrm{yuan} /(\mathrm{kW} \cdot \mathrm{h}) ; p_{h}$ is the current residential heating price in Beijing, $0.16 y u a n /(\mathrm{kW} \cdot \mathrm{h}) ; \eta_{c, r}$ is the cooling efficiency of the room air conditioners, estimated at 2.65 by the National Standard of China GB12021.3-2010 (AQSIQ and SAC, 2010). 

corresponding heating and cooling loads $\left(Q_{V, h}\right.$ and $\left.Q_{V, c}\right)$ as follows:

$$
M_{V}=\frac{a \cdot p_{e}}{10^{3} A \cdot \eta_{c, p}} \int Q_{V, c} \mathrm{~d} \tau+\frac{a \cdot p_{h}}{10^{3} A} \int Q_{V, h} \mathrm{~d} \tau
$$

where $\eta_{c, p}$ is the average cooling efficiency of ground source heat pumps, which is mostly used for the ventilation cooling sources, estimated at 3.08 by the National Standard of China GB/T19409-2013 (AQSIQ and SAC, 2013).

The fan power of the mechanical ventilation system $\left(M_{V P}\right)$ is calculated as follows:

$$
M_{V P}=0.365 \frac{p_{e} \cdot \tau_{I A} \cdot a \cdot D_{V P}}{A}
$$

where $D_{V P}$ is the input power of the mechanical ventilation system. According to Stephens et al. (2010), the energy consumption caused by the variation of filter efficiencies is negligible when set against the whole energy consumption of the mechanical ventilation system. Therefore, we assume a constant $D_{V P}=45 \mathrm{~W}$ for all the mechanically ventilated scenarios, which is taken from the Construction Industry Standard of China JG/T391-2012 (MOHURD, 2012).

The calculation of the heating and cooling loads of infiltration and mechanical ventilation airflows $\left(Q_{I, h}, Q_{I, c}, Q_{V, h}\right.$, and $\left.Q_{V, c}\right)$ are introduced in the Supplemental Information (SI3). Finally, the economic benefit of building ventilation energy can be expressed as:

$$
E B_{\text {energy }}=M_{B E}^{\prime}-M_{B E}
$$

where $M_{B E}^{\prime}$ means the economic cost of the building ventilation energy for the basic scenario.

\section{Results}

\subsection{Indoor $\mathbf{P M}_{2.5}$ concentrations}

Fig.4 shows the averages and standard deviations of indoor $\mathrm{PM}_{2.5}$ concentrations with different cooking activities, which are expressed as "breakfast/lunch/supper minutes." The resultant indoor concentrations of the basic scenario are also shown for comparison. The horizontal solid and dashed lines in Fig.4(a) are the guideline $\left(10 \mu \mathrm{g} / \mathrm{m}^{3}\right)$ and interim target- $1\left(35 \mu \mathrm{g} / \mathrm{m}^{3}\right)$ of the WHO, respectively. 


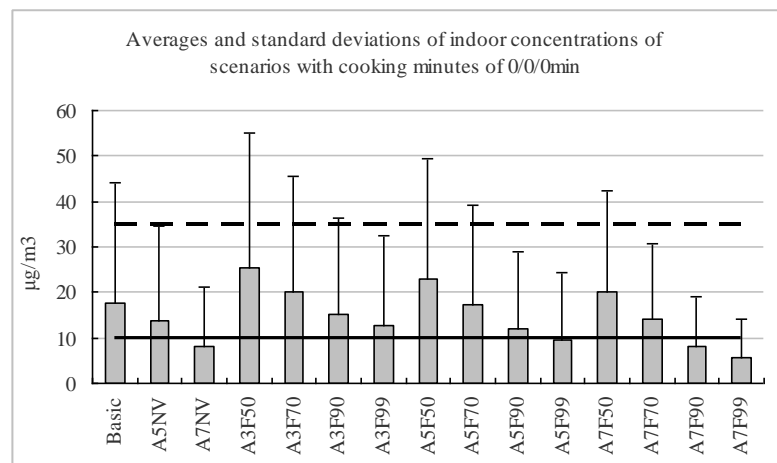

(a) $0 / 0 / 0 \min$
326

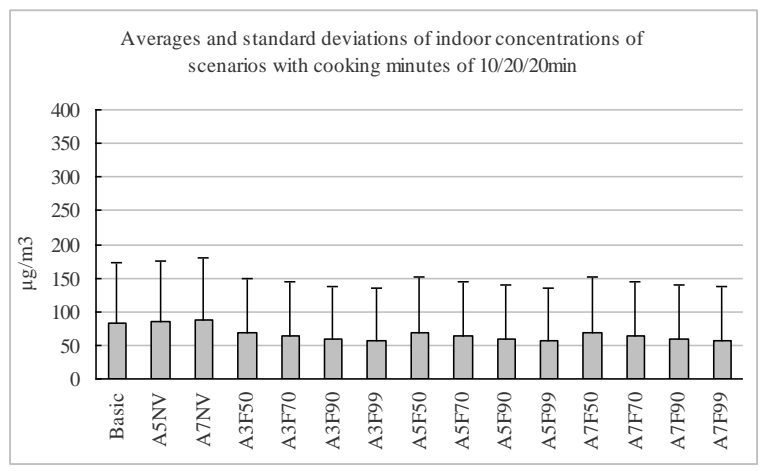

(b) $10 / 20 / 20 \mathrm{~min}$

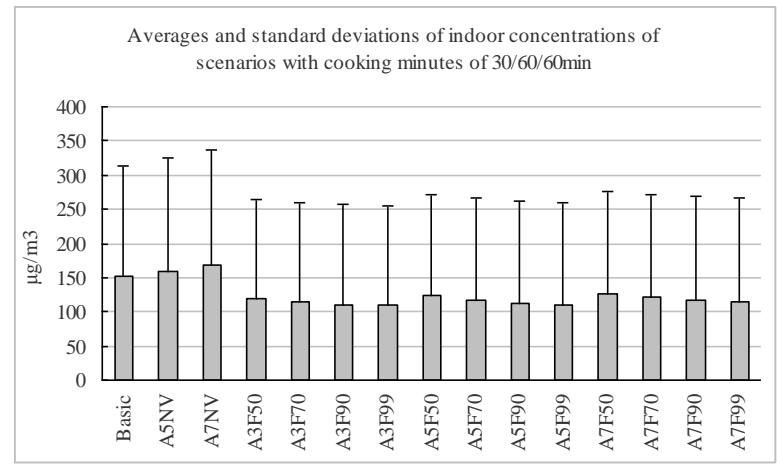

(d) $30 / 60 / 60 \mathrm{~min}$

(c) $20 / 40 / 40 \mathrm{~min}$

Fig.4: Averages and standard deviations of indoor $\mathrm{PM}_{2.5}$ concentrations

The indoor $\mathrm{PM}_{2.5}$ concentrations are greatly affected by the cooking emissions, though the cooking duration is divided into 3 periods and no more than 2.5 hours in total per day. The averages and standard deviations all increase significantly with the increase of cooking duration. As depicted in Fig.4(a), the annual averages for all scenarios are below the interim target-1 of the WHO, while the annual averages of scenarios A7NV (ATL7 without mechanical ventilation), A7F90 (ATL7, PFE=90\%) and A7F99 (ATL7, PFE=99\%) fall below the WHO guideline. However, when the cooking duration becomes longer, as shown in Fig.4 (c) and (d), the annual averages for all scenarios are even higher than the annual average ambient $\mathrm{PM}_{2.5}$ concentration $\left(81 \mu \mathrm{g} / \mathrm{m}^{3}\right)$.

Fig.4(a) also shows that when there is no indoor source, although most of the scenarios can reduce the indoor concentrations, the scenarios with $\mathrm{PFE}=50 \%$ could lead to higher indoor concentrations compared with the basic scenario. This is because the mechanical ventilation system under this low filtration efficiency could draw substantial amounts of $\mathrm{PM}_{2.5}$ into the indoor space. 
342 ventilation systems would always decrease the indoor concentration, while increasing air-tightness

343 without mechanical ventilation slightly leads to the opposite effect. That is because the air supplied

344 from the mechanical ventilation system can dilute the indoor-generated pollutants, while the high

345 level of air-tightness prevents the exfiltration of the indoor particles.

346 The standard deviations in Fig.4(a) show similar variation characteristics with the averages,

347 indicating that without indoor sources, the appropriate interventions can not only reduce the indoor

348 concentration levels, but also control the fluctuation of the indoor concentration in the long-term.

349 However, in Fig.4(b) to (d), with the same indoor emission strength and ventilation conditions (with

350 or without a mechanical ventilation system), the standard deviations of different scenarios do not vary

351 significantly. That is because the indoor emissions become the main influencing factor of the long-

352 term average concentration.

353

\subsection{Total economic benefits}

For all the intervention scenarios with different cooking activities, the total annual economic benefits are shown in Fig.5. The separate analysis of public health and energy cost is presented in the Supplement Information (SI4 and SI5).

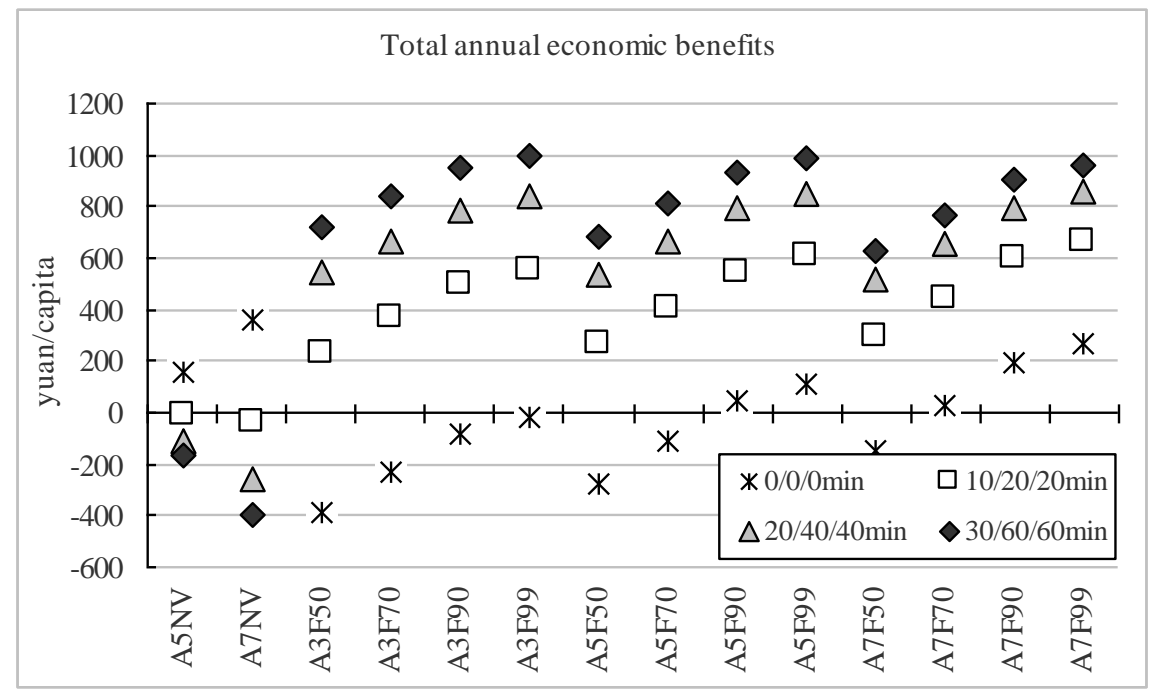

Fig.5: Total annual economic benefits

From the results in Fig.5, the following observations can be made: 
(1) For the scenarios without indoor $\mathrm{PM}_{2.5}$ emission, the economic benefits of most of the scenarios are below or near zero, while only the scenarios A7NV, A7F90, and A7F99 can achieve positive economic benefits greater than 200yuan/capita. However, scenario A7NV is not recommended as only improving air-tightness without supplying additional outdoor air could give rise to an accumulation of other indoor pollution, for example $\mathrm{CO}_{2}$, VOCs, and potential negative health consequences.

(2) For the scenarios without mechanical ventilation, the benefits are positive and grow with the increase of the air-tightness if there is no indoor $\mathrm{PM}_{2.5}$ source. However, the benefits will fall and become negative if an indoor source exists, indicating that the effect of solely improving air-tightness without installing mechanical ventilation is not a cost-effective intervention for the occupants when the real situation of indoor emission is taken into account.

(3) If an indoor $\mathrm{PM}_{2.5}$ source and mechanical ventilation coexist in the building, the economic benefits of the scenarios with the same filtration efficiency vary slightly with the air-tightness level, while the benefits of the scenarios with the same air-tightness level increase significantly with the improvement of the filtration efficiency. Moreover, the benefits of all the mechanically ventilated scenarios range from 234yuan/capita (A3F50) to 1,001yuan/capita (A3F99), and increase with the indoor emission strength. Thus, if there is indoor emission, the enhancement of filtration efficiency is an effective strategy which can reduce indoor $\mathrm{PM}_{2.5}$ exposure and achieve significant economic benefits.

(4) Though the scenario A3F50 has the least benefit among all the modelling results, A7F90 and A7F99 are the only two scenarios which can always achieve economic benefits above 200yuan/capita with different indoor emission conditions. Considering the uncertainty of the cooking style and duration, and a further extension to all the building types in urban Beijing, the high level of airtightness and mechanical ventilation with high $\mathrm{PM}_{2.5}$ filtration efficiency are both important.

\section{Discussion}


The annual average ambient PM2.5 concentration of Beijing in 2015 is $82.57 \mu \mathrm{g} / \mathrm{m} 3$, which is much higher than those in other 96 global largest cities studied in Stephens et al. (2016). Therefore, such high level of ambient $\mathrm{PM}_{2.5}$ concentration of Beijing could lead to an elevated indoor $\mathrm{PM}_{2.5}$ exposure to outdoor origin compared to those western studies. For different ventilation scenarios without indoor $\mathrm{PM}_{2.5}$ emissions, the annual averages of indoor $\mathrm{PM}_{2.5}$ concentrations range from 5.52 to $25.24 \mu \mathrm{g} / \mathrm{m}^{3}$ (Fig.4(a)), and the estimated mortality reduction ratios $\left(\Delta H / H^{\prime}\right)$ range from -2.65 to $4.23 \%$. However, for 22 U.S. cities, among which the largest annual ambient $\mathrm{PM}_{2.5}$ concentration was still less than $20 \mu \mathrm{g} / \mathrm{m}^{3}$, Zhao et al. (2015) found that for different home types with different filters in the USA, the annual average indoor $\mathrm{PM}_{2.5}$ concentrations were from 0.11 to $3.70 \mu \mathrm{g} / \mathrm{m}^{3}$, and the estimated mortality reduction ratios ranged from 0 to $2.5 \%$, which are much smaller than our results.

Furthermore, our study demonstrated that a high filtration efficiency (>90\%) should be adopted in Beijing in response to the high outdoor air pollution. The result is in good agreement with the study by Stephens et al. (2016), where the filters with $\mathrm{PM}_{2.5}$ filtration efficiency above $96 \%$ were recommended for outdoor air intakes in Beijing in order to keep the indoor exposure to outdoor $\mathrm{PM}_{2.5}$ under $12 \mu \mathrm{g} / \mathrm{m}^{3}$. According to our modelling results in Fig.4(a), without consideration of indoor emission, the Scenario A3F99 (with current air tightness level ATL3 and mechanical ventilation system with $\mathrm{PM}_{2.5}$ filtration efficiency of $99 \%$ ) could keep indoor concentration down to $12.82 \mu \mathrm{g} / \mathrm{m}^{3}$. The slight difference between the two studies can be attributed to the different outdoor $\mathrm{PM}_{2.5}$ concentrations used in these two studies. While in other cities especially in US and European countries where the outdoor air pollution level is low, the recommended filtration efficiency is much lower. For example, an effective filtration efficiency of $45 \%$ could be sufficient to reduce the burden of disease around 38\% in European countries (Hänninen and Asikainen, 2013).

411 The Chinese cooking style is another important factor that greatly influences the modelling results.

412 The cooking emission rate used in our study represents typical Chinese stir-fry cooking style (Gao et 413 al., 2013) and is much higher than that of $1.7 \mathrm{mg} / \mathrm{min}$ (Ozkaynak et al. (1996), which has been widely 
adopted in western studies. To compare the impact of indoor emission strength, we conduct an extra modelling with the cooking emission rate as $1.7 \mathrm{mg} / \mathrm{min}$. The results of total economic benefits for typical emission duration (20/40/40 mins) are shown in Fig.6. Two distinct features could be observed for the two cooking styles (Figure 6 versus Figure 5): (1) For the scenarios without mechanical ventilation, increase of air tightness can achieve positive economic benefits with Western cooking style, while the Chinese cooking style leads to negative outcomes; (2) For the scenarios with mechanical ventilation, the economic benefits with western cooking style are much smaller than those with Chinese cooking style, and some scenarios with low filtration efficiency become negative (e.g. A3F50, A3F70, A5F50).

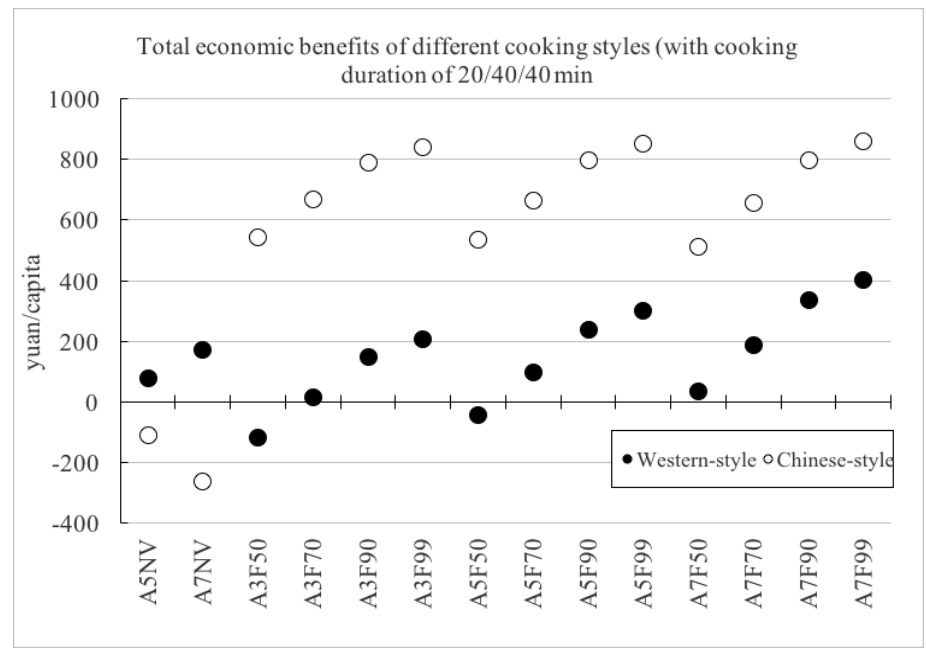

Fig.6: Comparison of annual economic benefits with two types of indoor emission: Western style

The impacts of indoor emissions in this study are broadly consistent with several existing studies. By a simulation of London's domestic housing stock, Shrubsole et al. (2012) showed that cooking contributed most of the indoor exposure to $\mathrm{PM}_{2.5}$, and the reductions of envelope permeability without mechanical ventilation would increase the indoor $\mathrm{PM}_{2.5}$ concentrations. The simulation conducted by Milner et al. (2015) revealed that even with mechanical ventilation, a higher level of air-tightness might still increase the pollutant concentrations due to indoor emissions. Both Milner et al. (2015) and Spilak et al. (2014) showed that mechanical ventilation with high filtration efficiency can reduce the indoor $\mathrm{PM}_{2.5}$ exposure. 
4.3 Discussion on the different building ventilation interventions

According to Fig.4(a), which represent the impact of the interventions on indoor $\mathrm{PM}_{2.5}$ exposure of outdoor origin only, increasing the envelope air-tightness can significantly reduce the indoor exposure to $\mathrm{PM}_{2.5}$ of outdoor origin. This finding is generally consistent with the modeling results from six unoccupied office buildings (no indoor source) in Beijing and Guangzhou measured for two months in winter (Chen et al., 2016). It can also be seen from Fig.4(a) that with the same air tightness, implementing mechanical ventilation with $\mathrm{PFE} \leq 70 \%$ will increase indoor exposure to $\mathrm{PM}_{2.5}$ of outdoor origin compared to buildings without mechanical ventilation. According to the experiment conducted by Stephens and Siegel (2012), the improper installation of residential mechanical ventilation systems without effective filtration might lead to inadvertent increases in human exposure to outdoor air pollution comparing to the infiltration-only scenario. All the three studies, including ours, suggest that the filtration efficiency of residential mechanical ventilation is very important to prevent the ingress of outdoor-generated pollution.

Our study shows that most of the health benefits of mechanically ventilated scenarios without indoor emissions are lower than the energy costs, including 4 scenarios with negative health outcomes. For the scenarios with positive health benefits, the benefit-to-cost ratios vary from 0.08 to 4.24 . This finding can be discussed with the theoretical studies on building interventions for reducing indoor exposure to PM of outdoor origin in Singapore (Zuraimi, 2007) and Toronto (Zuraimi and Tan, 2015). The study in Singapore aimed at indoor $\mathrm{PM}_{10}$ exposure found that the monetary health benefits of all assessed interventions (including filter efficiency enhancement, adopting air conditioning, etc.) were significantly higher than the costs in residential and office buildings. However, the study in Toronto, Canada found that the costs of retrofitting existing homes and implementing different residential building regulations were estimated at 2.3-2.9 times of the monetary health benefits of reducing indoor $\mathrm{PM}_{2.5}$ exposure. It should also be noticed that the cost analysis was different in the three studies: our study only considered the energy costs in operation; the study of Singapore included costs of air-conditioners, energy consumption, etc.; while the study of Toronto included both capital and operational costs of the building retrofits. Despite the cost items, the variation of the benefit-cost relations among the three studies might also be due to different GDPs in different countries. 
463 Considering the diversity of climates and differences in atmospheric environment status, the effects of

464 the building ventilation interventions in different regions in China should be estimated in a further 465 study.

\section{Limitations}

In our study, we provided only general assessments and central estimates of the magnitude of various uncertainties. Sensitivity analysis has not been conducted in this study. In fact, in the modelling to evaluate the effect of building ventilation interventions, the most uncertain input parameter is the indoor emission condition. The cooking time setting, as listed in Table 2, has taken the reasonable household cooking durations into account. There are some inherit limitations for the adopted massbalance model assuming e.g. complete mixing, and using a single compartment approach does not capture short-term variations in the actual exposure concentrations very well (McGrath et al, 2017), however, from the point of view of quantifying the overall exposure processes the accuracy is considered good (Hänninen and Asikainen, 2013). Other parameters such as penetration factor and deposition rate may give rise to uncertainty as well. According to the studies on indoor PM of Beijing, the influence of deposition rate is much stronger than penetration factor (Ji and Zhao, 2015(a); Shi et $a l ., 2017)$. However, the annual characteristics of penetration factor and deposition rate are influenced by many factors such as the geometry features of indoor space and instant indoor/outdoor air speeds (Chen and Zhao, 2011), while the long-term study on these two parameters is still absent in China. Therefore, we adopted values of penetration factor and deposition rate that have been widely used in other international studies. The comprehensive sensitivity analysis can be included in future research to refine uncertainty.

The modelling of health impacts is limited by the absence of two basic data sets. Firstly, since the concentration-response (C-R) coefficient of long-term $\mathrm{PM}_{2.5}$ exposure is largely absent in China at present (Shang et al., 2013), we use the C-R coefficient from the study conducted in the U.S. by Pope et al. (2002), which has been widely recognized around the world and used by several studies in 
in China may be different from that in developed countries due to different pollution levels, local population sensitivity, age distribution and, especially, different air pollution components (Cao et al., 2011; Zhang et al., 2014). Secondly, the value of a statistical life (VSL) applied in this study is derived from a survey in 2010 (Xie, 2011). With the rapid economic growth and urban development, the population structure and public health concerns in 2015 (the studied year) may be different from 6 years earlier, resulting in a changed VSL. However, research on these two parameters is beyond the scope of this paper, while the adopted values are the most reliable at present. and labour costs, which vary greatly and are strongly influenced by the actual forms of windows and mechanical ventilation systems. In China, the initial investment in building ventilation interventions is often paid by the government or included in the residence prices, while the operation costs are usually paid by the users. However, though the capital costs are reasonable for not being included in the modelling of economic benefits, these cost items should be considered in any further study if the benefits are discussed from the viewpoint of different stakeholders, such as the government, property developers and residents.

\section{Conclusion}

This study provides new insights into the economic benefits of building ventilation interventions for reducing indoor $\mathrm{PM}_{2.5}$ exposure from both indoor and outdoor origins in urban Beijing - one of the most polluted cities in the world. The modelling results demonstrate that with the variety of indoor $\mathrm{PM}_{2.5}$ emission sources, the cost-effectiveness of different building ventilation interventions can be different.

510 Without indoor $\mathrm{PM}_{2.5}$ emission, increasing envelope air-tightness can significantly reduce indoor

$511 \mathrm{PM}_{2.5}$ exposure and achieve health and economic benefits. However, if indoor emissions are present, the economic benefits of increasing air-tightness alone (without mechanical ventilation) will be negative. If indoor emission and mechanical ventilation coexist in the building, increasing air-

514 tightness will only slightly contribute to the positive economic benefits. 
For the buildings with indoor $\mathrm{PM}_{2.5}$ emission sources, the annual economic benefits of installing mechanical ventilation range from 200yuan/capita to 800yuan/capita. However, if there is no indoor emission, the annual economic benefits of installing mechanical ventilation will be above 200yuan/capita only when the $\mathrm{PM}_{2.5}$ filtration efficiency is no less than $90 \%$ and the envelope airtightness is above National Standard Level 7. Mechanical ventilation with $\mathrm{PM}_{2.5}$ filtration efficiency below $70 \%$ will carry substantial amounts of $\mathrm{PM}_{2.5}$ into the indoor space and lead to negative economic benefits if there is no $\mathrm{PM}_{2.5}$ source in the building. interventions in different climates and locations may vary significantly. Considering the diversity of climates and the differences in atmospheric environment status across China, further study should be conducted in different regions to provide effective building intervention strategies and achieve health and economic benefits nationwide.

\section{Acknowledgement}

\section{References}

AQSIQ, SAC, 2008(a). Air filters (GB/T14295-2008). National Standard of China

AQSIQ, SAC, 2008(b). Graduations and test methods of air permeability, water tightness, wind load resistance performance for building external windows and doors (GB/T7106-2008). National Standard of China

AQSIQ, SAC, 2008(c). High efficiency particulate air filter (GB/T13554-2008). National Standard of China

AQSIQ, SAC, 2010. The minimum allowable value of the energy efficiency and energy efficiency grades for room air conditioners (GB12021.3-2010). National Standard of China 
AQSIQ, SAC, 2011. Range hood (GB/T17713-2011). National Standard of China

AQSIQ, SAC, 2013. Water-source (ground-source) heat pumps (GB/T19409-2013). National Standard of China

Beijing Municipal Bureau of Statistics, NBS Survey Office in Beijing, 2016. Beijing statistical yearbook 2016. http://www.bjstats.gov.cn/nj/main/2016-tjnj/zk/indexeh.htm

BMCUP, BMAQTS, 2012. Design standard for energy efficiency of residential buildings (DB11/8912012). Local Standard of Beijing

Cao, J., Yang, C., Li, J., Chen, R., Chen, B., Gu, D., Kan, H., 2011. Association between long-term exposure to outdoor air pollution and mortality in China: A cohort study. J Hazard Mater. 186, $1594-1600$

Chen, Z., Chen, C., Wei, S., Wu, Y., Wang, Y., Wan, Y., 2016. Impact of the external window crack structure on indoor $\mathrm{PM}_{2.5}$ mass concentration. Build Environ. 108, 240-251

Cohen, A.J., Brauer, M., Burnett, R., Anderson, H.R., Frostad, J., Estep, K., et al., 2017. Estimates and 25-year trends of the global burden of disease attributable to ambient air pollution: An analysis of data from the Global Burden of Diseases Study 2015. Lancet. 389, 1907-1918

Dimitroulopoulou, C., Ashmore, M.R., Hill, M.T.R., Byrne, M.A., Kinnersley, R., 2006. INDAIR: A probabilistic model of indoor air pollution in UK homes. Atmos Environ. 40, 6362-6379

Fabian, P., Adamkiewicz, G., Levy, J.I., 2012. Simulating indoor concentrations of $\mathrm{NO}_{2}$ and $\mathrm{PM}_{2.5}$ in multifamily housing for use in health-based intervention modelling. Indoor Air. 22, 12-23

Fang, D., Wang, Q., Li, H., Yu, Y., Lu, Y., Qian, X., 2016. Mortality effects assessment of ambient $\mathrm{PM}_{2.5}$ pollution in the 74 leading cities of China. Sci Total Environ. 569-570, 1545-1552

Gao, J., Cao, C., Wang, L., Song, T., Zhou, X., Yang, J., Zhang, X., 2013. Determination of sizedependent source emission rate of cooking-generated aerosol particles at the oil-heating stage in an experimental kitchen. Aerosol Air Qual Res. 13, 488-496

Hänninen, O., Asikainen, A., 2013. Efficient reduction of indoor exposures - Health benefits from optimizing ventilation, filtration and indoor source controls. ISBN 978-952-245-822-3 (online publication) 
He, C., Morawska, L., Hitchins, J., Gilbert, D., 2004(a). Contribution from indoor sources to particle number and mass concentrations in residential houses. Atmos Environ. 38, 3405-3415

He, L., Hua, M., Huang, X., Yu, B., Zhang, Y., Liu,D., 2004(b). Measurement of emissions of fine particulate organic matter from Chinese cooking. Atmos Environ. 38, 6557-6564

Huang, D., Zhang, S., 2013. Health benefit evaluation for $\mathrm{PM}_{2.5}$ pollution control in Beijing-TianjinHebei region of China. China environmental science. 33, 166-174

Ji, W., Zhao, B., 2015(a). Contribution of outdoor-originating particles, indoor-emitted particles and indoor secondary organic aerosol (SOA) to residential indoor $\mathrm{PM}_{2.5}$ concentration: A modelbased estimation. Build Environ. 90, 196-205

Ji, W., Zhao, B., 2015(b). Estimating mortality derived from indoor exposure to particles of outdoor origin. PLoS ONE 10(4): e0124238. doi:10.1371/journal.pone.0124238

Kan, H.D., Chen, B.H., 2004. Particulate air pollution in urban areas of Shanghai, China: health-based economic assessment. Sci Total Environ. 322(1-3), 71-79

Klepeis, N.E., Nelson, W.C., Ott, W.R., Robinson, J.P., Tsang, A.M., Switzer, P., Behar, J.V., Hern, S.C., Engelmann, W.H., 2001. The national human activity pattern survey (NHAPS): a resource for assessing exposure to environmental pollutions. J Expo Anal Env Epid. 11, 231-252

Lee, S.C., Li, W.M., Chan, L.Y., 2001. Indoor air quality at restaurants with different styles of cooking in metropolitan Hong Kong. Sci Total Environ. 279, 181-193

Long, C.M., Suh, H.H., Koutrakis, P., 2000. Characterization of indoor particle sources using continuous mass and size monitors. J Air Waste Manage. 50(7), 1236-1250

Lü, L., Li, H., 2016. Health Economic Evaluation of $\mathrm{PM}_{10}$ and $\mathrm{PM}_{2.5}$ Pollution in Beijing-TianjinHebei Region of China. Acta Scientiarum Naturalium Universitatis Nankaiensis. 49(1), 69-77

McGrath, J.A., Sheahan, J.N., Dimitroulopoulou, C., Ashmore, M.R., Terry, A.C., Byrne, M.A., 2017. PM exposure variations due to different time activity profile simulations within a single dwelling. Build Environ. 116, 55-63

Milner, J., Hamilton, I., Shrubsole, C., Das, P., Chalabi, Z., Davies, M., Wilkinson, P., 2015. What should the ventilation objectives be for retrofit energy efficiency interventions of dwellings? Build Serv Eng Res T. 36(2), 221-229 
MEP, 2016. China Environmental Status Bulletin 2015. http://www.zhb.gov.cn/hjzl/zghjzkgb/ lnzghjzkgb/

MOHURD, 2010. Design standard for energy efficiency of residential buildings in severe cold and cold zones (JGJ26-2010). Industry Standard of China

MOHURD, 2012. Ventilators (JG/T391-2012). Construction industry Standard of China

Montgomery, J.F., Reynolds, C.C.O., Rogak, S.N., Green, S.I., 2015. Financial implications of modifications to building filtration systems. Build Environ. 85, 17-28

Ozkaynak, H., Xue, J., Spengler, J., Wallace, L., Pellizzari, E., Jenkins, P., 1996. Personal exposure to airborne particles and metals: results from the particle team study in Riverside, California. $\mathrm{J}$ Expo Anal Env Epid. 6(1), 57-78

Pope III, C.A., Burnett, R.T., Thun, M.J., Calle, E.E., Krewski, D., Ito, K., Thurston, G.D., 2002. Lung cancer, cardiopulmonary mortality, and long-term exposure to fine particulate air pollution. JAMA-J Am Med Assoc. 287(9), 1132-1141

Shang, Y., Sun, Z., Cao, J., Wang, X., Zhong, L., Bi, X., Li, H., Liu, W., Zhu, T., Huang, W., 2013. Systematic review of Chinese studies of short-term exposure to air pollution and daily mortality. Environ Int. 54, 100-111

Shi, S., Chen, C., Zhao, B., 2015. Air infiltration rate distributions of residences in Beijing. Build Environ. 92, 528-537

Shi, S., Chen, C., Zhao, B., 2017. Modifications of exposure to ambient particulate matter: Tackling bias in using ambient concentration as surrogate with particle infiltration factor and ambient exposure factor. Environ Pollut. 220, 337-347

Shrubsole, C., Ridley, I., Biddulph, P., Milner, J., Vardoulakis, S., Ucci, M., Wilkinson, P., Chalabi, Z., Davies, M., 2012. Indoor $\mathrm{PM}_{2.5}$ exposure in London's domestic stock: Modelling current and future exposures following energy efficient refurbishment. Atmos Environ. 62, 336-343

Song, C., He, J., Wu, L., Jin, T., Chen, X., Li, R., Ren, P., Zhang, L., Mao, H., 2017. Health burden attributable to ambient $\mathrm{PM}_{2.5}$ in China. Environ Pollut. 223, 575-586 
Spilak, M.P., Karottki, G.D., Kolarik, B., Frederiksen, M., Loft, S., Gunnarsen, L., 2014. Evaluation of building characteristics in 27 dwellings in Denmark and the effect of using particle filtration units on $\mathrm{PM}_{2.5}$ concentrations. Build Environ. 73, 55-63

Stephens, B., 2015. Building design and operational choices that impact indoor exposures to outdoor particulate matter inside residences, Sci Technol Built En. 21(1), 3-13

Stephens, B., Brennan, T., Harriman, Lew., 2016. Selecting ventilation air filters to reduce $\mathrm{PM}_{2.5}$ of outdoor origin. ASHRAE JOURNAL. 58(9), 12-20

Stephens, B., Siegel, J.A., 2012. Comparison of test methods for determining the particle removal efficiency of filters in residential and light-commercial central HVAC systems. Aerosol Sci Tech. $46,504-13$

Stephens, B., Siegel, J.A., Novoselac, A., 2010. Energy implications of filtration in residential and light-commercial buildings. ASHRAE Trans 2010. 116, 346-57

Viscusi, W.K., Aldy, J.E, 2003. The value of a statistical life: A critical review of market estimates throughout the world. J Risk Uncertainty. 27(1), 5-76

Wan, M., Wu, C., To, G.S., Chan, T., Chao, C.Y.H., 2011. Ultrafine particles and $\mathrm{PM}_{2.5}$ generated from cooking in homes. Atmos Environ. 45, 6141-6148

World Health Organization (WHO), 2006. WHO Air quality guidelines for particulate matter, ozone, nitrogen dioxide and sulfur dioxide: Global update 2005: Summary of risk assessment

Xie, X., 2011. The value of health: environmental valuation and control strategy study of urban air pollution. Doctoral dissertation of Peking University

Xie, Y., Chen, J., Li, W., 2014. An Assessment of PM $_{2.5}$ Related Health Risks and Impaired Values of Beijing Residents in a Consecutive High-Level Exposure during Heavy Haze Days. Environmental Science. 35(1), 1-8

Zhang, L., Chen, X., Xue, X., Sun, M., Han, B., Li, C., Ma, J., Yu, H., Sun, Z., Zhao, L., Zhao, B., Liu, Y., Chen, J., Wang, P.P., Bai, Z., Tang, N., 2014. Long-term exposure to high particulate matter pollution and cardiovascular mortality: A 12-year cohort study in four cities in northern China. Environ Int. 62, 41-47 
Zhao, D., Azimi, P., Stephens, B., 2015. Evaluating the long-term health and economic impacts of central residential air filtration for reducing premature mortality associated with indoor fine particulate matter $\left(\mathrm{PM}_{2.5}\right)$ of outdoor origin. Inter J Env Res Pub Heal. 12, 8448-8479

651 Zhou, B., Zhao, B., 2012. Population inhalation exposure to polycyclic aromatic hydrocarbons and associated lung cancer risk in Beijing region: Contributions of indoor and outdoor sources and exposures. Atmos Environ. 62, 472-480

654 Zuraimi, M.S., 2007. Estimates of associated outdoor particulate matter health risk and costs

655 reductions from alternative building, ventilation and filtration scenarios. Sci Total Environ. 377,

$656 \quad 1-11$

657 Zuraimi, M.S., Tan, Z., 2015. Impact of residential building regulations on reducing indoor exposures to outdoor $\mathrm{PM}_{2.5}$ in Toronto. Build Environ. 89, 336-344 